mediastudies.press • Social Media \& the Self: An Open Reader

\title{
The Age of Instagram Face
}

\section{Jia Tolentino}

Published on: Dec 12, 2019

DOI: $10.32376 / 3 f 8575 c b .760 d b 98 a$

License: Creative Commons Attribution-NonCommercial 4.0 International License (CC-BY-

NC 4.0). 
THIS PAST SUMMER, I booked a plane ticket to Los Angeles with the hope of investigating what seems likely to be one of the oddest legacies of our rapidly expiring decade: the gradual emergence, among professionally beautiful women, of a single, cyborgian face. It's a young face, of course, with poreless skin and plump, high cheekbones. It has catlike eyes and long, cartoonish lashes; it has a small, neat nose and full, lush lips. It looks at you coyly but blankly, as if its owner has taken half a Klonopin and is considering asking you for a private-jet ride to Coachella. The face is distinctly white but ambiguously ethnic-it suggests a National Geographic composite illustrating what Americans will look like in 2050, if every American of the future were to be a direct descendant of Kim Kardashian West, Bella Hadid, Emily Ratajkowski, and Kendall Jenner (who looks exactly like Emily Ratajkowski). "It's like a sexy ... baby ... tiger," Cara Craig, a high-end New York colorist, observed to me recently. The celebrity makeup artist Colby Smith told me, "It's Instagram Face, duh. It's like an unrealistic sculpture. Volume on volume. A face that looks like it's made out of clay."

Instagram, which launched as the decade was just beginning, in October, 2010, has its own aesthetic language: the ideal image is always the one that instantly pops on a phone screen. The aesthetic is also marked by a familiar human aspiration, previously best documented in wedding photography, toward a generic sameness. Accounts such as Insta Repeat illustrate the platform's monotony by posting grids of indistinguishable photos posted by different users-a person in a yellow raincoat standing at the base of a waterfall, or a hand holding up a bright fall leaf. Some things just perform well....

continue reading

\section{OUTBOUND LINK}

“The Age of Instagram Face" (Jia Tolentino, The New Yorker, December 12, 2019)

METERED PAYWALL (4 free articles per month) 